\title{
USE OF WATER EXTRACT OF MORINGA OLEIFERA SEEDS (WEMOS) IN RAW WATER TREATMENT IN MAKURDI, NIGERIA
}

\author{
I. M. AHO AND J. C. AGUNWAMBA
}

\begin{abstract}
Availability of clean water is a serious problem, especially in developing countries like Nigeria, where conventional treatment methods are inappropriate due to high cost and low availability of chemical coagulants like alum. The paper presents the use of moringa seeds extract as alternative to alum in raw water treatment. Preliminary engineering properties such as jar test, speeds of flocculation; 98, 196 and 260rpm; detention and setting times were conducted to determine the integrity of moringa extract as a natural coagulant. The results shows that at the speed of 98rpm and settling time of 1 hour, $85-89 \%$ removal of solids was achieved, while $41-59 \%, 63-80 \%$ removal of solids were possible at $260 \mathrm{rpm}$ and 196rpm respectively. Similarly, after 2 hours of settling time, $93-96 \%, 64-75 \%, 65-80 \%$ removal of solids were obtained at $98 \mathrm{rpm}, 260 \mathrm{rpm}$ and $196 \mathrm{rpm}$ respectively. The treatment suggests optimum performance at low and medium speeds better than maximum speed of flocculation. It is suggested that further investigation be carried out on particle sizes of moringa oleifera seeds powder.
\end{abstract}

KEYWORDS: Moringa-oleifera, seeds, extract, raw water, treatment.

\section{INTRODUCTION}

The conventional methods of water treatment involves various water clarification processes which includes coagulation, flocculation, sedimentation and disinfection. These methods are often not suitable because of the high cost and low availability of chemical coagulants and disinfectants. Moreso, the dosages and techniques involved are too cumbersome for use in most rural areas (Aho, and and Lagasi, 2012). Alum used as coagulant at local levels can have adverse effects on water (Folkard et al, 2006). These problems are well recognized by the international community, such that Governments and non-governmental organizations (NGOs) have been making massive worldwide efforts over the years to solve it; yet, the problems still remains (Kalogo \& Verstraete, 2000). In order to alleviate these difficulties, new approaches are now being adopted, to focus on sustainable water treatment systems that are low cost and robust with minimal maintenance and operational skills. It is in the light of the above that this study is set up to experiment on the use of moringa seeds extract in raw water treatment in Benue State.

Moringa oleifera according to Lowel (2001), is a small, fast growing, drought "deciduous" tree that ranges in height from 5 $12 \mathrm{~m}$ with an open, umbrella shaped trunk which when fully grown is straight with corky and whitish bark. The evergreen foliage has leaflets $1-2 \mathrm{~cm}$ in diameter, the flowers are white or cream coloured. The fruits are initially light green slim and tender, eventually becoming dark green, firm and up to $120 \mathrm{~cm}$ long.

Moringa oleifera can easily be planted by transplanting or by seed. The seed can be sown either directly or in containers with no seed treatment necessary. The plants raised from 1 mere beat, pods from the second year. Thereafter, it grows with maximum production of 4 to 5 years.

In a favourable environment like Southern Nigeria, an individual tree can yield 50 to $70 \mathrm{~kg}$ of pods in one year. Originally considered a tree of hot semi-arid regions (annual rainfall

I. M. Aho, Department of Civil Engineering, University of Agriculture, Makurdi, Nigeria.

J. C. Agunwamba, Department of Civil Engineering, University of Nigeria, Nsukka, Nigeria. 
$250-1500 \mathrm{~mm}$ ), but now found to be well adapted to humid and wet conditions with annual rainfall in excess of $3000 \mathrm{~mm}$. In most states of Northern Nigeria especially Benue, fresh moringa leaves are eaten as vegetables, roots for medicinal purposes while the seeds are usually thrown away.

\section{MATERIALS AND METHODS}

\section{Seed sampling and preparation}

Seeds of moringa oleifera plant were obtained within Makurdi metropolis. The seedpods were allowed to mature and dry naturally to a brown colour on the trees before harvesting. To obtain the water extract of moringa, the finely crushed seed powder $10 \mathrm{grams}$ were mixed with $100 \mathrm{ml}$ of clean water to form paste. The insoluble material was removed by filtering the paste through a funnel containing cotton wool into $100 \mathrm{ml}$ containers.
Jar test

Varying amounts of water extract of moringa oleifera seeds (WEMOs) were flocculated rapidly and slowly for 15 minutes. The settled turbidity and suspended solids were measured and correct coagulant dosages determined.

Determination of suspended solids (SS), turbidity, temperature and $\mathrm{pH}$ of water samples

Photometric method was adopted in the measurement of suspended solids as described by Baker (1980).

For turbidity, a DR/2000 model 1990 spectrophotometer was adopted. A long stem thermometer was used by inserting into the water samples. The values of the temperatures were read after allowing in for 5 minutes. Similarly, $\mathrm{pH}$ readings were taken with a $\mathrm{pH}$ meter model 1125.

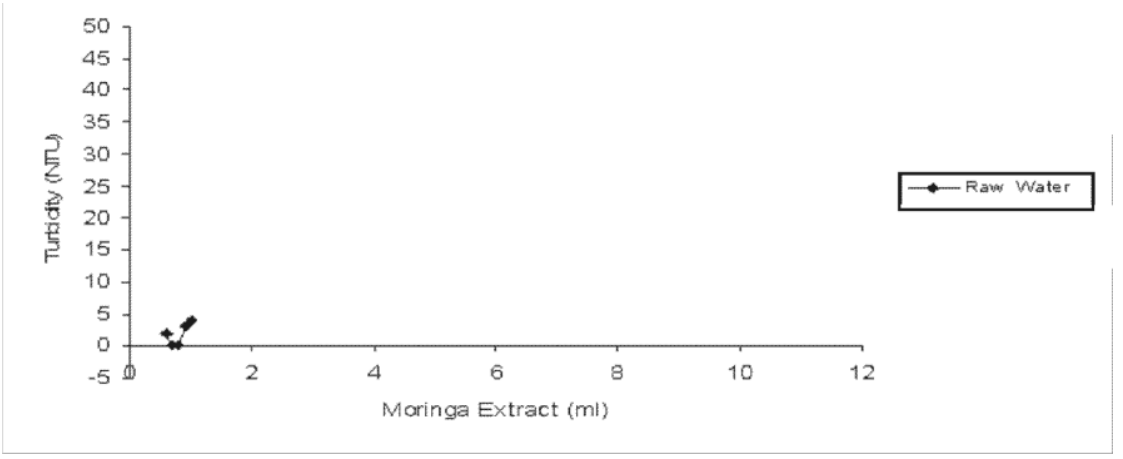

Fig. 1: Jar test analysis for raw and waste water using moringa extract 


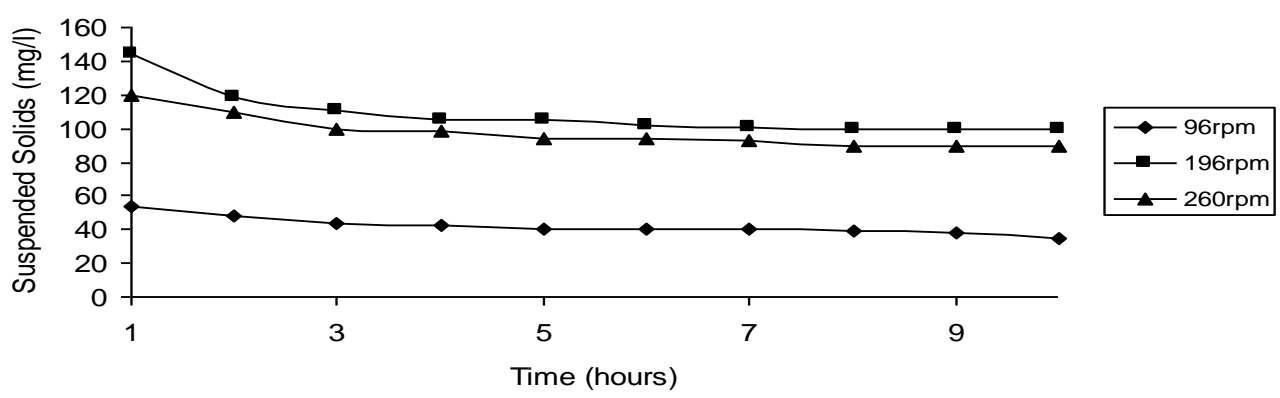

Fig. 2: Suspended solids versus time after 1hour of settling time of moringa extract in waste water

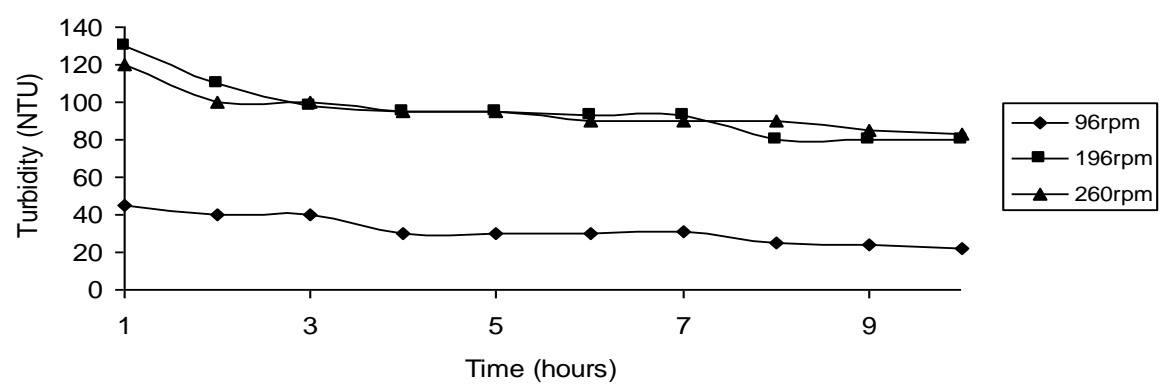

Fig. 3: Turbidity versus time after 1 hour of settling time of moringa extract in waste water

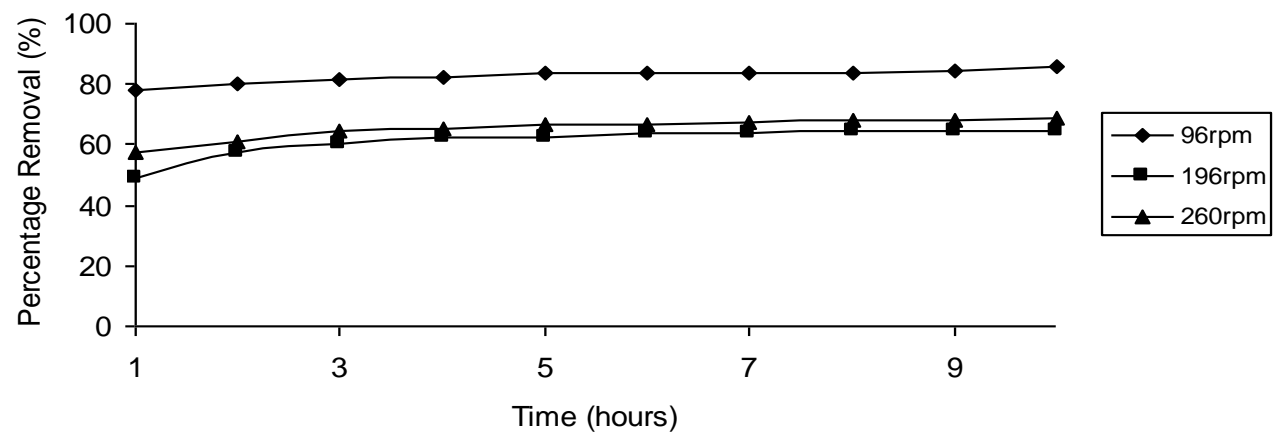

Fig. 4: Percentage removal of suspended solids versus time after 1hour of settling time of moringa extract in waste water. 


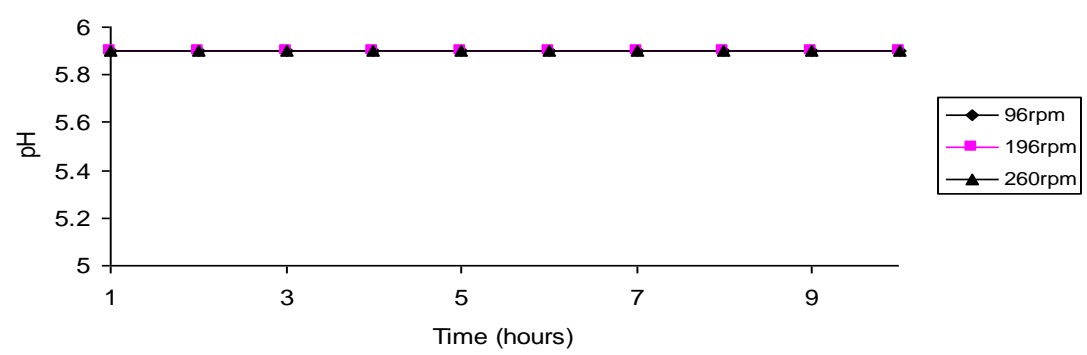

Fig. 5: $\mathrm{pH}$ versus time after 1 hour of settling time of moringa extract in waste water.

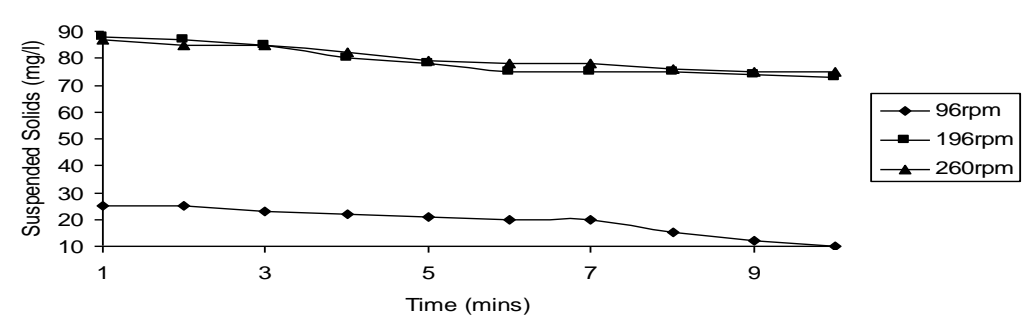

Fig.6: Suspended solids versus time after 2 hours of settling time of moringa extract in waste water

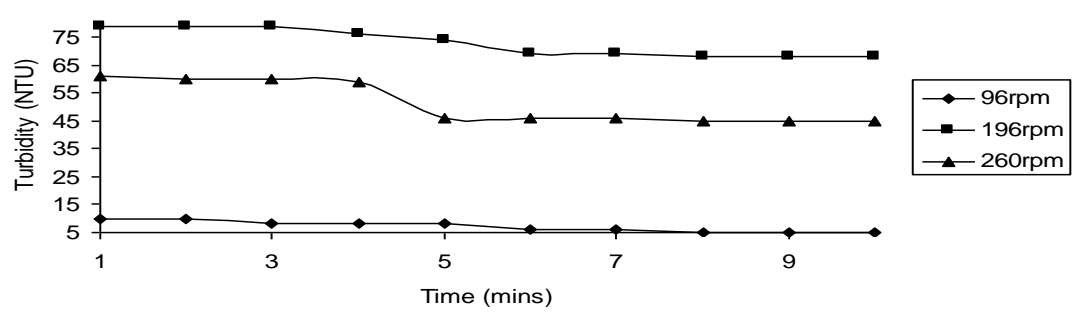

Fig. 7: Turbidity versus time after 2 hours of settling time of moringa extract in waste water

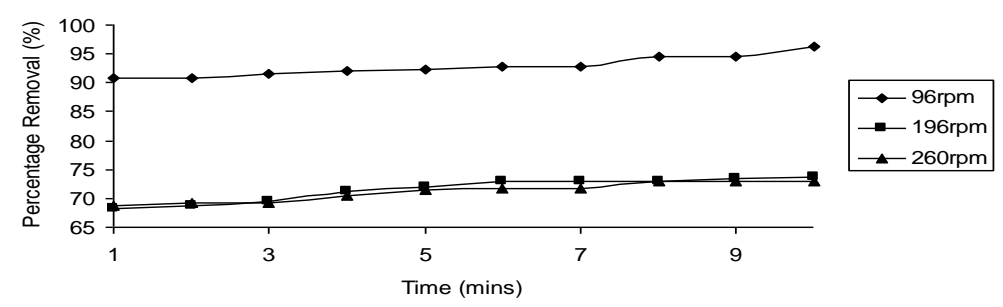

Fig. 8: Percentage removal of suspended solids versus time after 2 hours of settling time of moringa extract in waste water. 


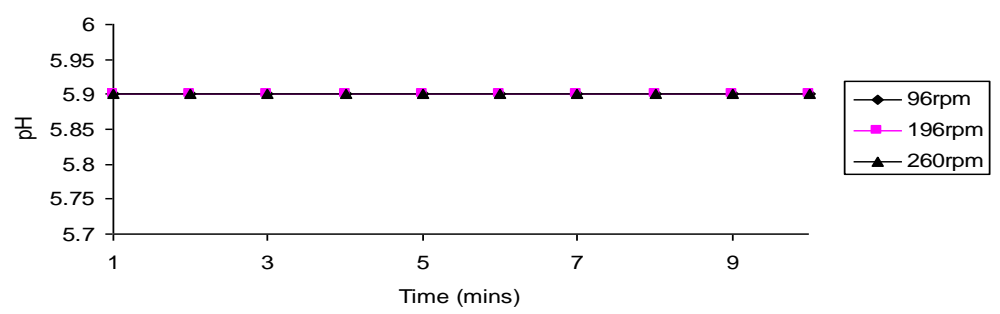

Fig.9: $\mathrm{pH}$ versus time after 2 hours of settling time of moringa extract in waste water.

\section{RESULTS AND DISCUSSION}

The result of the jar test analysis gave optimum dosage as presented in figure 1.0. The analysis shows that 8 milliliters of the extract coagulant is capable of treating raw water that has slight to moderate turbidity not exceeding 250 NTU. Consequently, the assessed water parameters after 1 hour of settling time is presented as shown in figures $2-5$. At $98 \mathrm{rpm}$, 196rpm and 260rpm, $85-89 \%, 41-59 \%, 63-$ $80 \%$ removal of suspended solids were observed. After two hours of detention period, the treatment efficiencies were increased for both parameter removals as shown in figures $6-9$. The treatment indicates optimum performance in the removal of solids and turbidity at the low speed of 96rpm, and at 2 hours of detention time. Furthermore, the use of the extract coagulant is capable of reducing the $\mathrm{pH}$ of the treated water marginally, but not significant enough to affect the quality of the water.

\section{CONCLUSION}

From the study carried out, the coagulative efficiency of using moringa seed extract in raw water treatment is almost $100 \%$, when compared with alum commonly used in conventional water treatment. But in terms of availability, moringa oleifera seed extract is considered a better alternative because of high cost and non-biodegradabiltiy of the organic alum coagulant. However, the use of moringa oleifera seed powder in particle sizes is recommended for further investigation.

\section{REFERENCES}

Aho, I. M and Lagasi, J. E., 2012. A New Water Treatment System Using Moringa Oleifera Seed. American Journal of Scientific and Industrial Research. 3, (6): $487-492$.

Baker, F. I., 1980. Medical Microbiology Techniques. $3^{\text {rd }}$ Edition White Friars Press London.

Folkard, G., John, S and Rega, S. A. 2006. Water Clarification Using Moringa Oleifera Seed Coagulant. Yahoo.mailjudithfate2006@yahoo.com.

Kalogo, Y and Verstraete, W., 2000. Technical Feasibility of the Treatment of Domestic Waste and Raw Water. Environmental Technology 21, 55-65.

Lowel, J. F., 2001. Introduction to Moringa Family. Church World Service, Dakar Senegal. 